\title{
Effect of Sunshine Duration on Myopia in Primary School Students from Northern and Southern China
}

\author{
Lin Leng' \\ Jiafan Zhang' \\ Sen $\mathrm{Xie}^{2}$ \\ Wenzhi Ding' \\ Rongyuan Ji \\ Yuyin Tian' \\ Keli Long' \\ Hongliang $\mathrm{Yu}^{3}$ \\ Zhen Guo'
}

'Department of Ophthalmology, Qingdao Eye Hospital of Shandong First Medical University, State Key Laboratory Cultivation Base, Shandong Provincial Key Laboratory of Ophthalmology, Shandong Eye Institute, Shandong First Medical University \& Shandong Academy of Medical Sciences, Qingdao, 26607I, Shandong Province, People's Republic of China; ${ }^{2}$ Department of Ophthalmology, Zhongshan Ophthalmic Center, Sun YatSen University, Guangzhou, 510000, Guangdong Province, People's Republic of China; ${ }^{3}$ Department of Ophthalmology, Shenyang Eye Docloud Internet Hospital, Shenyang, I 10000 , Liaoning Province, People's Republic of China

Correspondence: Zhen Guo Qingdao Eye Hospital of Shandong First Medical University, State Key Laboratory Cultivation Base, Shandong Provincial Key Laboratory of Ophthalmology, Shandong Eye Institute, Shandong First Medical University \& Shandong Academy of

Medical Sciences, Qingdao, 26607I, Shandong Province, People's Republic of China

Tel +86 532-87610198

Email guoz@sdfmu.edu.cn
Background: To assess the current myopia prevalence rate and evaluate the effect of sunshine duration on myopia among primary school students in the north and south of China. Methods: This prospective cross-sectional study pooled data from 9171 primary school students (grades from 1 to 6) from four cities in the north and south of China. National Geomatics Center of China (NGCC) and China Meteorological Administration provided data about altitude, latitude, longitude, average annual temperature, and average annual sunshine duration. Non-cycloplegic refraction was recorded, and prevalence rates in primary school students and factors associated with myopia were analyzed. Univariate and multivariate logistic regression models were used to determine the independent association of risk factors of myopia.

Results: The overall myopia prevalence was $28.0 \%$, from $7.5 \%$ to $50.6 \%$ for first and sixth grades, respectively. Low, moderate and high myopia significantly increased with school grades from $7.30 \%$ to $35.0 \%, 0.3 \%$ to $13.60 \%$ and $0.00 \%$ to $1.9 \%$, respectively. Multiple regression analysis revealed that longer average cumulative daylight hours were connected to lower myopia prevalence in primary school students (OR, 0.721; 95\% CI, [0.593-0.877]; $\mathrm{P}=0.001$ ), whereas girls and higher grade was independently associated with higher myopia prevalence (girls: $\beta=0.189$; OR, 1.208; 95\% CI, [1.052-1.387]; $\mathrm{P}=0.007$; higher grade: $\beta=0.502$; OR, 1.652; 95\% CI, [1.580-1.726]; $\mathrm{P}<0.001)$.

Conclusion: This study demonstrated that myopia was highly prevalent in southern Chinese cities over northern ones, linked to shorter light exposure, higher education level, and female gender. Such findings reinforced the beneficial impact of daylight exposure with a protective role against myopia development.

Keywords: myopia, epidemiology, sunshine duration, China

\section{Introduction}

Myopia has already been the most prevalent eye disease worldwide with vision impairment, with the anticipated number of patients growing from the current 2620 million to approximately 4758 million in 2050, affecting approximately $50 \%$ of the global population. ${ }^{1}$ The World Health Organization (WHO) reported that myopia is more prevalent in China, influencing almost 600 million people. $^{2}$ In addition, the incidence of myopia among Chinese students aged 7-18 years is among the highest in the world, which may be related to the development of China's education system. ${ }^{3}$ It is mainly manifested in the heavy burden of schoolwork and numerous after-school classes. Epidemiological studies showed that $67 \%$ 
of students spent less than 2 hours in outdoor activities a day, $29 \%$ of students spent less than 1 hour, and $73 \%$ of students did not sleep up to the standard. ${ }^{4}$ High myopia is strongly linked to other co-existing eye complications, such as myopic maculopathy, choroidal neovascularization, cataract, retinal detachment and glaucoma. ${ }^{5-8}$ Given the growing number of cases globally, myopia is on the rise as a major public health problem (WHO 2015). ${ }^{2}$

Despite the unclear myopia cause in children, major known risk factors comprising age, female sex, time spent outdoors, urbanization, educational attainment, prenatal factors and high-risk genes appear to be of crucial importance. $^{9-11}$ However, unfortunately, some of these factors cannot be altered to decrease myopia risk. Therefore, research efforts are increasingly devoted to behavior or environment-related factors that affect myopia. Population-based studies have shown that time spent playing sports outdoors was linked to myopia. However, Guggenheim et $\mathrm{al}^{12}$ concluded that the time spent outdoors could predict myopia incidence regardless of the physical activity level, which may be attributed to light exposure. Subsequently, several successive studies were conducted and focused on the short-term impact of sunshine duration on myopia among different seasons. ${ }^{13-15}$

Due to a lack of robust epidemiological data, the relationship between long-term sunshine duration and myopia incidence remains uncertain. Furthermore, myopia prevalence varies significantly according to ethnicity. ${ }^{16}$ China possesses a vast territory, with large latitude difference between northern and southern cities, providing convenient conditions to study the influence of different sunshine durations on myopia. Herein, we explored myopia prevalence among Chinese primary school students from coastal cities in different latitudes, followed by estimating the sunshine duration impact on myopia.

\section{Materials and Methods}

\section{Sample Selection and Review Board}

\section{Approval}

In this work, we conducted a school-based cross-sectional investigation of myopia prevalence in selected four urban coastal Chinese cities from October to November 2019. The four coastal cities include Shenyang City (Liaoning Province), Qingdao City (Shandong Province), Qingyuan City (Guangdong Province) and Fangchenggang City (Guangxi Province). With the Tropic of Cancer as the boundary, these cities are divided into northern
(Shenyang and Qingdao) and southern (Qingyuan and Fangchenggang) ones. All participants aged 6 to 12 years were elementary school students from grades 1 to 6 . Sample size was estimated on the basis of incidence of myopia reported in previous literature, which showed the prevalence of myopia was approximately $30 \%$ among primary school students, ${ }^{17,18}$ with a $5 \%$ SE, assuming a 2-sided $\alpha$ of 0.05 and participation rate of $90 \% .{ }^{19}$ The calculation results showed that the number of students in each region should be more than 359 .

The study sample was school-based and used a stratified random cluster design. For a complete representation, a selection was made of randomly chosen schools from four cities. All students from grades 1 to 6 among the selected schools were offered participation in the study unless they refused to join. All parents in each region were requested to sign an informed consent form after being informed of the study's purpose and procedures. The study received approval from the Institutional Review Board of Shandong Eye Institute and complied with the tenets of World Medical Association Declaration of Helsinki.

\section{Data Collection}

Each selected school provided demographic data of all subjects, including grade, gender and school location. The information of the last 10 years on latitude, longitude, altitude, average annual temperature, average annual sunshine duration of four coastal cities was obtained from National Geomatics Center of China (NGCC) and China Meteorological Administration. All study data were entered into the Juvenile myopia prevention and control screening system, and input data accuracy was confirmed by importing data into system using two data entry operators that verified it separately.

\section{Definitions}

Spherical equivalent (SE) was calculated according to the standard formula "SE $=$ sphere $+1 / 2$ cylinder". To make the results comparable, myopia was defined as $\mathrm{SE} \leq-0.50$ D. Myopia was categorized into low $(-3.00 \mathrm{D}<\mathrm{SE} \leq-0.50$ D), moderate $(-6.00 \mathrm{D} \leq \mathrm{SE}<-3.00 \mathrm{D})$ and high myopia $(\mathrm{SE} \leq-6.00 \mathrm{D}){ }^{20}$ This was also consistent with the Refractive Error Study in Children (RESC) protocol. $^{21}$ Meanwhile, emmetropia was defined as SE of greater than $-0.5 \mathrm{D}$ and less than $0.5 \mathrm{D}^{21,22}$

\section{Ophthalmic Assessment}

Ocular examinations were conducted by the trained eye-care professionals, comprising optometrists and ophthalmologists, 
who underwent training on RESC protocol, mastered the basic knowledge of myopia epidemiology, measurement methods, equipment usage and data-collection forms. Subsequently, all students underwent a comprehensive ophthalmological examination. Basic eye examinations included visual acuity (VA) measurements, non-cycloplegic refractometry and subjective refraction. VA of each eye was examined by skilled doctors using a retroilluminated Early Treatment Diabetic Retinopathy Study chart with tumbling-E optotypes. Before conducting VA testing, we asked all participants whether they wore glasses, contact lens or orthokeratology contact lens. If the students did not wear glasses, their uncorrected visual acuity (UCVA) of each eye was tested by optometrists. For children wearing frame glasses, VA was measured both with glasses as presenting VA and without glasses as UCVA, excluding those with contact lens or orthokeratology contact lens.

In this work, non-cycloplegic refraction was deployed to assess myopia prevalence. Autorefractors (RM-9600, Nidek Corp., Tokyo, Japan) were used to test refractive error of each eye at least three times. When one measurement differed from the other two $(>0.50 \mathrm{D})$, measurements were repeated followed by determining the average of three reliable measurements. ${ }^{23,24}$

Experienced ophthalmologists utilized slit lamps and indirect ophthalmoscopes to examine the eyelids, conjunctiva, cornea, iris, pupil, lens, vitreous and fundus. Exclusion criteria included ocular diseases (corneal degeneration, keratoconus, cataract, glaucoma, strabismus, and amblyopia et.al), eye surgery and injuries.

\section{Statistical Analyses}

The data were exported in Excel format from the Juvenile myopia prevention and control screening system, followed by data analysis using SPSS software (version 19.0, IBMSPSS, Chicago, IL, USA). Data were described as mean \pm standard deviation. The myopia prevalence in different groups was statistically described, expressed as cases or percentages. Pearson Chi-squared tests evaluated prevalence of myopia differences between grades, genders, latitude, average annual temperature, and average annual sunshine duration. Univariate and multivariate logistic regression models were utilized to assess the independent association of each risk factor with myopia prevalence. A two-tailed $P<$ 0.05 was considered to be statistically significant. Through Pearson correlation analysis, a high degree of correlation of eye examination values is found between right and left eyes $(\mathrm{P}<0.05)$. Accordingly, this study only involved statistical analysis of the right eye data.

\section{Results}

A total of 9367 students from four coastal Chinese cities were requested to participate in the current study, with 41 individuals being excluded from the study due to ocular diseases. Of the 9326 eligible participants, 114 declined to join (Figure 1). Consequently, data from 9171 children (4911 boys, $53.6 \%$ ) were analyzed and mean age of students was $8.83 \pm 1.48$ years. The distribution of subjects enrolled in each city was as follows: Shenyang City (2278 subjects), Qingdao City (2262 subjects), Qingyuan City (2300 subjects) and Fangchenggang City (2331 subjects). The details of demographic data in various grades of students from four cities are shown in Table 1.

The overall myopia prevalence in primary school students was $28.0 \%$. The four coastal cities demonstrate different myopia prevalence: Shenyang City (24.5\%), Qingdao City (26.4\%), Qingyuan City (28.1\%) and Fangchenggang City (31.3\%). The northern and southern schools showed no intergroup differences in the value of UCVA $(0.11 \pm 0.23$ vs $0.14 \pm 0.22, \mathrm{P}=0.08)$ and presenting VA $(0.10 \pm 0.01$ vs $0.13 \pm 0.15, \mathrm{P}=0.56)$. The average annual sunshine duration, average annual temperature, altitude, latitude, longitude and myopia prevalence among participants of these four cities are displayed Table 2.

Figure 2 represents the prevalence rates of myopia in each grade range between northern and southern schools. The total myopia prevalence gradually augmented from first grade to sixth grade in primary school as of $7.50 \%$, $13.20 \%, 21.4 \%, 31.40 \%, 44.60 \%, 50.60 \%$, respectively.

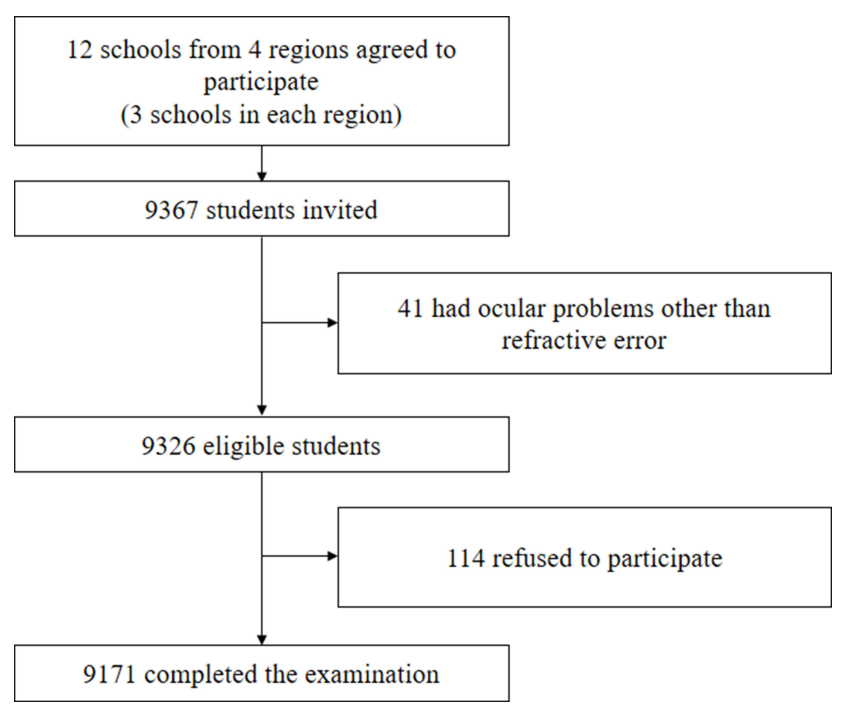

Figure I Flowchart showing the process of screening participants. 
Table I Characteristics of Demography in Different Grades of Students from 4 Cities

\begin{tabular}{|l|c|c|c|c|}
\hline & Shenyang & Qingdao & Qingyuan & Fangchenggang \\
\hline Number & 2278 & 2262 & 2300 & 2331 \\
Grade I (\%) & $375(16.5)$ & $376(16.6)$ & $377(16.4)$ & $382(16.4)$ \\
Grade 2 (\%) & $399(17.5)$ & $373(16.5)$ & $402(17.5)$ & $375(16.0)$ \\
Grade 3 (\%) & $399(17.1)$ & $396(17.5)$ & $400(17.4)$ & $414(16.5)$ \\
Grade 4 (\%) & $377(16.5)$ & $373(16.4)$ & $375(16.3)$ & $373(17.8)$ \\
Grade 5 (\%) & $362(15.9)$ & $370(16.4)$ & $354(15.4)$ & $376(16.1)$ \\
Grade 6 (\%) & $376(16.5)$ & $374(16.5)$ & $392(17.0)$ & $411(17.7)$ \\
Male (\%) & $1191(52.3)$ & $1202(53.1)$ & $1242(54.0)$ & $1276(54.7)$ \\
\hline
\end{tabular}

Table 2 Sample Characteristics and Myopia Prevalence Among Schoolchildren in Different Regions

\begin{tabular}{|l|c|c|c|c|}
\hline & Shenyang & Qingdao & Qingyuan & Fangchenggang \\
\hline Annual Sunshine duration (h) & 2495 & 2075 & 1632 & 1896 \\
Annual Temperature ( $\left.{ }^{\circ} \mathrm{C}\right)$ & 9 & 14 & 21.1 & 28.4 \\
Altitude (m) & 50 & 77 & 32 & 15 \\
Latitude (degree) & $41^{\circ} 48^{\prime} \mathrm{N}$ & $36^{\circ} 06^{\prime} \mathrm{N}$ & $24^{\circ} 49^{\prime} \mathrm{N}$ & $21^{\circ} 45^{\prime} \mathrm{N}$ \\
Longitude (degree) & $123^{\circ} 23^{\prime} \mathrm{E}$ & $120^{\circ} 19^{\prime} \mathrm{E}$ & $112^{\circ} 29^{\prime} \mathrm{E}$ & $108^{\circ} 21^{\prime} \mathrm{E}$ \\
Myopia prevalence (\%) & 24.5 & 26.4 & $28 . I^{\prime}$ & 31.3 \\
\hline
\end{tabular}

The myopia prevalence from first to sixth grade in the northern group was lower than that in the southern group, except for the third grade $(22.10 \%$ in the northern group and $21.40 \%$ in the southern group).

As presented in Figure 3, the continuous relationship between educational attainment and SE is stratified according to different participants' regions. A significant negative correlation was noticeable between school grades and SE. The total SE varied with school grades: from mean SE of $+0.37 \mathrm{D}$ in the first grade to $-1.22 \mathrm{D}$ in the sixth grade, highlighting the SE shift towards myopia as the grade increased. Mean SE values from grades 1 to 6 were $+0.64 \mathrm{D},+0.29 \mathrm{D},-0.04 \mathrm{D},-0.32 \mathrm{D},-0.63 \mathrm{D}$ and

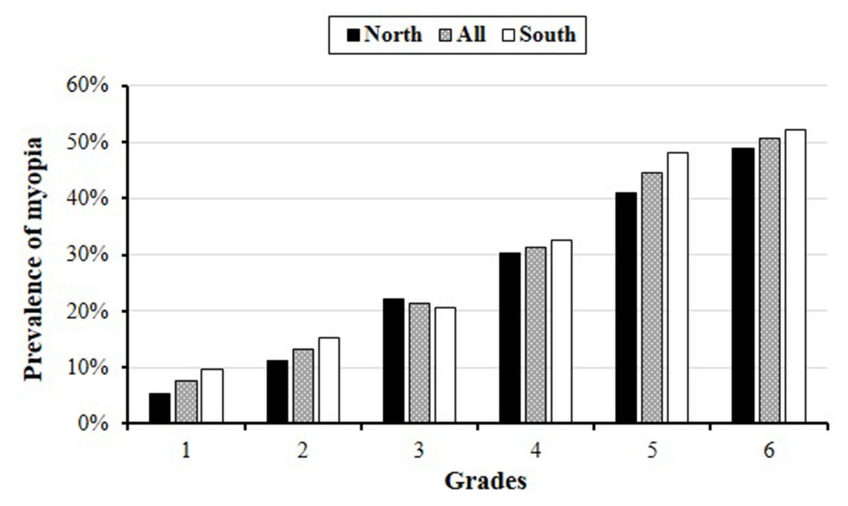

Figure 2 Distribution of myopia between north and south school children by Grades.
$-1.15 \mathrm{D}$ for northern school students, respectively, and $+0.11 \mathrm{D},-0.07 \mathrm{D},-0.33 \mathrm{D},-0.51 \mathrm{D},-1.13 \mathrm{D}$ and -1.29 $\mathrm{D}$ for southern school students. Students from southern primary schools had a lower mean SE with increasing grades than those from northern schools. These differences were statistically significant $(\mathrm{P}<0.001$ for grade 1 and 2 , $\mathrm{P}=0.001$ for grade $3, \mathrm{P}=0.037$ for grade $4, \mathrm{P}<0.001$ for grade 5), except for grade $6(\mathrm{P}=0.327)$.

Risk factors for the myopia are demonstrated in Table 3. The total myopia prevalence in boys was $26.5 \%$ (95\% CI, [24.7-28.3\%]) and that of girls was 29.8\% (95\% $\mathrm{CI},[27.8-31.8 \%])$. The prevalence rates of myopia in girls was higher than that in boys $\left(\chi^{2}=6.2, \mathrm{P}=0.013\right.$, Table 3$)$. The level of education was highly associated with the myopia prevalence $\left(\chi^{2}=559.8, \mathrm{P}<0.001\right.$, Table 3$)$. The total myopia prevalence increased from $7.5 \%(95 \% \mathrm{CI}$, [5.8-9.7\%]) in grade 1 to $50.6 \%(95 \% \mathrm{CI},[47.0-54.2 \%])$ in grade 6 . As the school grade increased, the prevalence of low, moderate and high myopia also increased respectively from $7.30 \%(95 \% \mathrm{CI},[5.5-9.4 \%])$ to $35.0 \%(95 \%$ CI, [31.7-38.5\%]), from $0.3 \%(95 \% \mathrm{CI},[0.0-1.0 \%])$ to $13.60 \%(95 \% \mathrm{CI},[11.3-16.3 \%])$ and from $0.00 \%(95 \%$ CI, $[0.0-0.5 \%])$ to $1.9 \%(95 \% \mathrm{CI},[1.1-3.2 \%])$. Areas with long average annual sunshine duration showed less myopia incidence. $\left(\chi^{2}=8.0, \mathrm{P}=0.018\right)$. Average annual temperature also appears to be related to myopia incidence $\left(\chi^{2}=9.7, \mathrm{P}=0.008\right)$ 


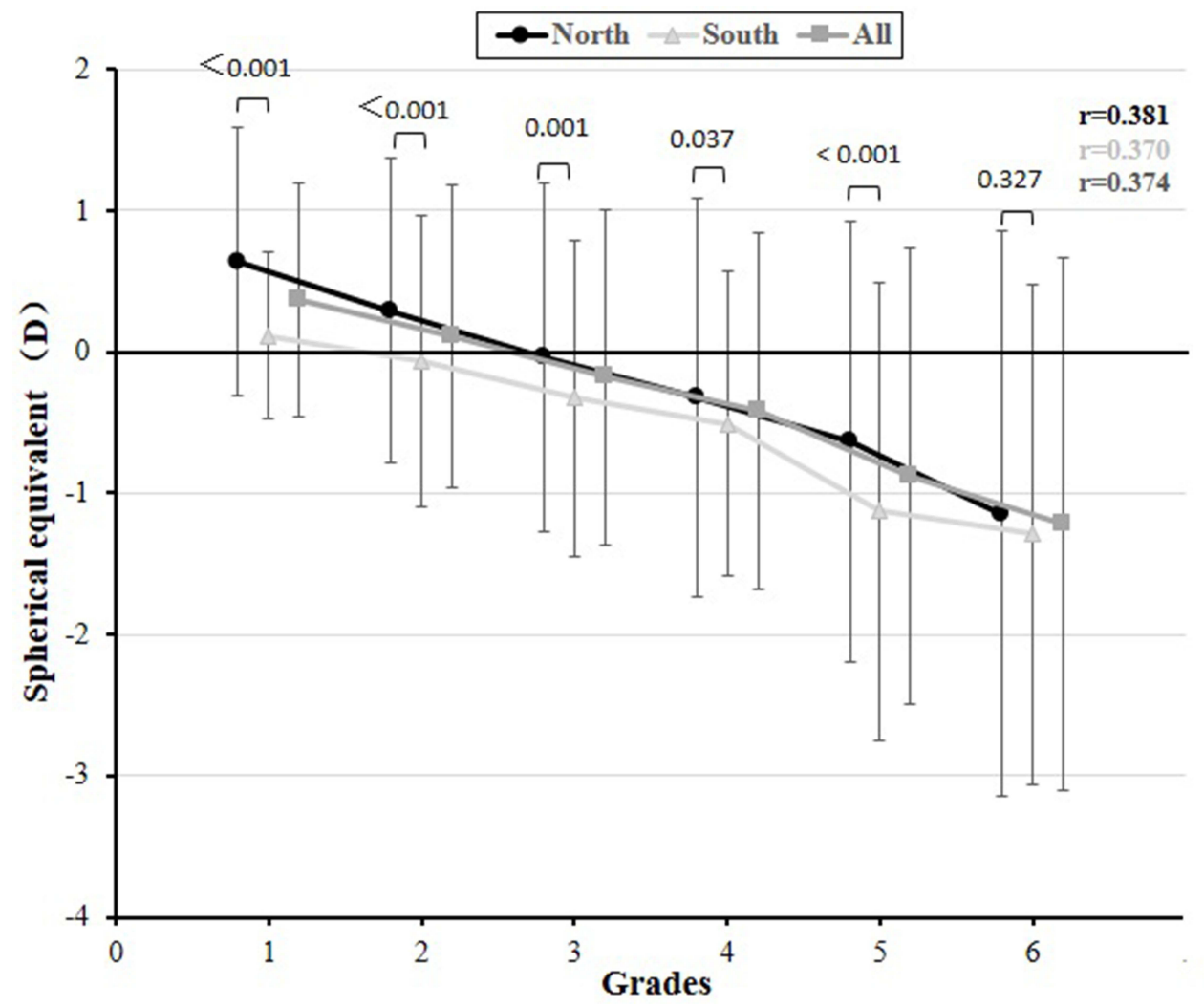

Figure 3 Distribution of spherical equivalent refractive error in different regions by grades. Error bars show SDs.

Univariate and multiple regression analysis were performed to estimate the risk factors for the myopia among participants (Table 4). In a univariate model, myopia was linked to girls $(\beta=0.163$; OR, $1.178 ; 95 \% \mathrm{CI},[1.035$ $1.340]$; $\mathrm{P}=0.013)$, higher grade $(\beta=0.5$; OR, 1.649; 95\% CI, [1.578-1.724]; $\mathrm{P}<0.001)$ and higher temperature $(\beta=0.247$; OR, 1.28; 95\% CI, [1.096-1.495]; $\mathrm{P}=$ 0.002). Nevertheless, longer average annual sunshine duration $(\beta=-0.227$; OR, 0.797; 95\% CI, [0.6790.937 ]; $\mathrm{P}=0.006$ ) was negatively correlated with myopia. In multivariate logistic regression analysis, myopia was only significantly associated with girls $(\beta=0.189$; OR, 1.208; 95\% CI, [1.052-1.387]; $\mathrm{P}=0.007)$, higher grade $(\beta=0.502$; OR, $1.652 ; 95 \%$ CI, [1.580-1.726]; $\mathrm{P}<0.001)$ and longer average annual sunshine duration $(\beta=-0.327 ;$ OR, 0.721; 95\% CI, [0.593-0.877]; $\mathrm{P}=$ $0.001)$.

\section{Discussion}

In this large-scale observational study, we evaluated the prevalence of myopia in Chinese coastal areas. We stated that the overall myopia prevalence was $28.0 \%$ among primary school students, and myopia prevalence rate increased from $7.50 \%$ in grade 1 to $50.60 \%$ in grade 6 . This trend of myopia is consistent with many other studies, showing that the prevalence of myopia increases universally with years of education. ${ }^{25-30}$ For instance, In Korea, the prevalence of myopia in children aged 5 to 18 years was $64.6 \%{ }^{25}$ In Nepal, prevalence in the urban was $10.9 \%, 16.5 \%$, and $27.3 \%$ in $10-, 12-$, and 15 - year olds, respectively. ${ }^{26}$ In Guangzhou, China, prevalence of myopia was $12.0 \%$ in grade 1 students and increased to $67.4 \%$ in grade 6 students. ${ }^{29}$ In Feicheng, China, due to the COVID-19 home confinement, students were confined to their homes from January to May, and online courses were offered. The prevalence of myopia increased dramatically, from $21.5 \%$ in the first grade to $59.5 \%$ in the sixth grade. ${ }^{30}$ Although it is challenging to compare the prevalence of myopia across studies due to variations in research design, measurement methods of refractive errors, study populations, and inconsistent definitions, ${ }^{31}$ we utilized the same definition to compare myopia among primary school students in various Chinese regions. Different prevalence rates of myopia between northern and southern regions exemplified myopia distribution in China, and this phenomenon cannot be explained by urbanization or 
Table 3 Myopia Severity Category by Gender, Grades, Average Annual Sunshine Duration, and Temperature

\begin{tabular}{|c|c|c|c|c|c|c|c|c|c|}
\hline \multirow[t]{2}{*}{ Risk Factors } & \multicolumn{2}{|c|}{ Low Myopia } & \multicolumn{2}{|c|}{ Moderate Myopia } & \multicolumn{2}{|c|}{ High Myopia } & \multicolumn{2}{|c|}{ All } & \\
\hline & $\begin{array}{c}\text { Prevalence, } \\
\%\end{array}$ & $95 \% \mathrm{Cl}$ & $\begin{array}{c}\text { Prevalence, } \\
\%\end{array}$ & $95 \% \mathrm{Cl}$ & $\begin{array}{c}\text { Prevalence, } \\
\%\end{array}$ & $95 \% \mathrm{Cl}$ & $\begin{array}{c}\text { Prevalence, } \\
\%\end{array}$ & $95 \% \mathrm{Cl}$ & \\
\hline \multicolumn{10}{|l|}{ Gender } \\
\hline Boys & 21.0 & $19.4-22.6$ & 5.0 & $4.2-5.9$ & 0.5 & $0.3-0.9$ & 26.5 & $24.7-28.3$ & $c^{2}=6.2$ \\
\hline Girls & 23.7 & $21.9-25.6$ & 5.6 & $4.6-6.6$ & 0.5 & $0.2-0.9$ & 29.8 & $27.8-31.8$ & $P=0.013$ \\
\hline \multicolumn{10}{|l|}{ Grades } \\
\hline 1 & 7.30 & $5.5-9.4$ & 0.30 & $0.0-1.0$ & 0.0 & $0.0-0.5$ & 7.5 & $5.8-9.7$ & $c^{2}=559.5$, \\
\hline 2 & 12.10 & $9.9-14.7$ & 0.90 & $0.4-1.9$ & 0.1 & $0.0-0.7$ & 13.2 & $10.9-15.8$ & $P<0.001$ \\
\hline 3 & 19.00 & $16.3-21.9$ & 2.30 & $1.3-3.5$ & 0.1 & $0.0-0.7$ & 21.4 & | $8.6-24.4$ & \\
\hline 4 & 26.60 & $23.5-29.9$ & 4.80 & $3.4-6.6$ & 0.0 & $0.0-0.5$ & 31.4 & $28.1-34.9$ & \\
\hline 5 & 33.90 & $30.5-37.5$ & 10.00 & $7.9-12.4$ & 0.7 & $0.2-1.6$ & 44.6 & $41.0-48.3$ & \\
\hline 6 & 35.00 & $31.7-38.5$ & 13.60 & $11.3-16.3$ & 1.9 & $1.1-3.2$ & 50.6 & $47.0-54.2$ & \\
\hline \multicolumn{10}{|c|}{$\begin{array}{l}\text { Annual sunshine } \\
\text { duration (hours) }\end{array}$} \\
\hline $\mid 500-1900$ & 24.00 & $22.3-25.8$ & 5.10 & $4.2-6.0$ & 0.6 & $0.4-1.1$ & 29.7 & $27.9-31.6$ & $c^{2}=8.0$ \\
\hline $1900-2300$ & 21.40 & $19.1-23.9$ & 5.40 & $4.2-6.9$ & 0.4 & $0.1-1.0$ & 27.3 & $24.7-30.0$ & $P=0.018$ \\
\hline 2300 & 19.50 & $17.2-21.9$ & 5.60 & $4.3-7.1$ & 0.2 & $0.0-0.6$ & 25.2 & $22.7-27.8$ & \\
\hline \multicolumn{10}{|c|}{$\begin{array}{l}\text { Annual temperature } \\
\left({ }^{\circ} \mathrm{C}\right)\end{array}$} \\
\hline $5-15$ & 20.40 & $18.8-22.2$ & 5.50 & $4.6-6.5$ & 0.3 & $0.1-0.6$ & 26.3 & $24.5-28.1$ & $c^{2}=9.7$ \\
\hline $15-25$ & 24.30 & $21.8-26.8$ & 3.20 & $2.3-4.4$ & 0.6 & $0.2-1.3$ & 28.1 & $25.5-30.8$ & $P=0.008$ \\
\hline 25 & 23.80 & $21.3-26.3$ & 6.90 & $5.5-8.5$ & 0.7 & $0.3-1.3$ & 31.3 & $28.6-34.1$ & \\
\hline
\end{tabular}

Note: $\mathrm{P}$ value was calculated using the Pearson Chi-squared tests, comparing the total prevalence among groups.

educational attainment. A preceding study manifested that refractive error prevalence was higher in urban $(51.2 \%)$ than rural group $(21.7 \%)$, with a significant difference. ${ }^{32}$ Considering this difference between urban and rural areas, all schools chosen in this study were located in the urban regions. In this work, the factors found to be independently and significantly associated with myopia included sex, grade, and annual sunshine duration. The distribution may help us develop intervention strategies to slow down the progression of myopia in areas with high incidence.

Epidemiological studies have revealed that outdoor time was the strongest environmental factor that can delay myopia onset. For instance, compared with EastAsians and some other Europeans, myopia onset was significantly delayed in Norwegians. ${ }^{33-35}$ Besides, Cui et al conducted a six-month cross-sectional survey on sunshine duration impact on myopia in Denmark. ${ }^{13}$ They reported that by increasing daylight hours, myopia progression decreased in children. Nevertheless, no long-term relevant research has been conducted in the same country and race that focused on relationship between sunshine duration and myopia. With its vast territory, China strides across latitude $3^{\circ} 51^{\prime} \sim 53^{\circ} 33^{\prime} \mathrm{N}$ from south to north, confirming its suitability for this research. Among these four Chinese cities, the annual average daylight length varies much more from 1632 hours to 2495 hours. We found that myopia prevalence was associated with sunshine duration, and southern cities demonstrated higher myopia prevalence than northern cities in all primary grades.

Our findings proposed that long average sunshine duration was a protective factor against myopia. Previous studies demonstrated that outdoor time had no relation to maintaining a higher level of physical exercise or spending less time reading, but to exposure to higher intensity light outdoors. ${ }^{36,37}$ A study from Guangdong of China showed that the myopia progression rate is lower in summer than in winter. ${ }^{14}$ However, it is unclear whether this phenomenon is ascribed to various close work activity levels during winter and summer periods or attributed to differences in day length. Since the distribution of school holidays in China is similar, myopia progression difference between south and north may not be caused by close work activity. Some researchers used conjunctival ultraviolet autofluorescence (UVAF) as a biomarker to assess the 
Table 4 Logistic Regression Analysis for Myopia, with Gender, Grade, Annual Sunshine Duration and Temperature as Risk Factors

\begin{tabular}{|c|c|c|c|c|c|c|c|c|}
\hline \multirow[t]{2}{*}{ Risk Factors } & \multicolumn{4}{|c|}{ Univariate Analysis } & \multicolumn{4}{|c|}{ Multiple Analysis } \\
\hline & $\beta$ & OR & $95 \% \mathrm{Cl}$ & $P$ value & $\boldsymbol{\beta}$ & OR & $95 \% \mathrm{Cl}$ & $P$ value \\
\hline \multicolumn{9}{|l|}{ Gender } \\
\hline Boys & & I & & & & I & & \\
\hline Girls & 0.163 & 1.178 & $1.035-1.340$ & 0.013 & 0.189 & 1.208 & $1.052-1.387$ & 0.007 \\
\hline Grade & 0.5 & 1.649 & $1.578-1.724$ & $<0.001$ & 0.502 & 1.652 & $1.580-1.726$ & $<0.001$ \\
\hline 1 & & & & & & & & \\
\hline 2 & & & & & & & & \\
\hline 3 & & & & & & & & \\
\hline 4 & & & & & & & & \\
\hline 5 & & & & & & & & \\
\hline 6 & & & & & & & & \\
\hline \multirow{2}{*}{\multicolumn{9}{|c|}{$\begin{array}{l}\text { Annual sunshine } \\
\text { duration (hours) }\end{array}$}} \\
\hline & & & & & & & & \\
\hline $1500-1900$ & & I & & & & I & & \\
\hline $1900-2300$ & -0.118 & 0.889 & $0.759-|.04|$ & 0.143 & -0.202 & 0.817 & $0.674-0.991$ & 0.04 \\
\hline 2300 & -0.227 & 0.797 & $0.679-0.937$ & 0.006 & -0.327 & 0.721 & $0.593-0.877$ & 0.001 \\
\hline \multicolumn{9}{|c|}{$\begin{array}{l}\text { Annual temperature } \\
\left({ }^{\circ} \mathrm{C}\right)\end{array}$} \\
\hline $5-15$ & & I & & & & I & & \\
\hline $15-25$ & 0.093 & 1.097 & $0.936-1.286$ & 0.254 & -0.157 & 0.854 & $0.706-1.035$ & 0.107 \\
\hline 25 & 0.247 & 1.28 & $1.096-1.495$ & 0.002 & & & & \\
\hline
\end{tabular}

Note: Significance $P$ value $<0.05$.

Abbreviations: $\mathrm{Cl}$, confidence interval; OR, odds ratio.

association between myopia and outdoor light exposure. ${ }^{38}$ They indicated that UVAF area was negatively correlated with myopia, meaning a lower UVAF level with more severe myopia. ${ }^{39,40}$ Experimentally, studies revealed that bright light outdoors held a protective function in developing myopia by regulating dopamine (DA) release $e^{41,42}$ and animal models also showed the protective effects of bright light against myopia, possibly via dopamine signaling. ${ }^{43,44}$ Although we did not collect each student's actual amount of outdoor light exposure, students might spend more time outdoors in regions with longer sunshine duration to a certain extent.

Herein, myopia prevalence rate was as high as $50.6 \%$ in sixth grade. The correlation with myopia by age or grade could not be analyzed alone. It is implicit that some of the differences in age could be the result of improved education. ${ }^{45}$ It has been speculated that higher education exposes successive cohorts of children to increased duration and intensity of near-work activity, which contribute to the development of myopia. ${ }^{46}$ Compared with people with lower education levels, those with higher education levels who had received more reading and other near work had a higher prevalence and severity of myopia. ${ }^{47}$ Considering the above reasons, we chose the grade factor to analyze the relevance of myopia. With the increasing education burden, myopia's rate and degree were getting worse, implying a potential additive impact of years of education. ${ }^{23,48,49}$ The increased educational activities require potentially less time spent outdoors, greater near work activities and increased use of computers. ${ }^{18,50}$

Girls had a higher prevalence and degree of myopia than boys, and several other studies demonstrated similar findings that myopia was negatively associated with male gender. ${ }^{49,51}$ While the cause for this discrepancy is currently unclear, one potential reason may be gender differences in patterns of activity as boys spend significantly more time outdoors, but girls are more engaged on near work. ${ }^{49}$ In China, girls are generally more diligent and studious than boys. However, there may be other reasons for this difference between boys and girls, such as genetic inheritance and puberty time, ${ }^{10}$ which requires additional investigation. 
Although the ambient temperature varies between the south and the north, it showed no myopia associations once other factors were considered, as evidenced by our findings. No relationship between ambient temperature and myopia occurrence has been reported before.

This study's strengths comprised a same race, a same country, a large sample size, and standardized refraction. Some limitations should be addressed. First, we did not use cycloplegics in the current study, and the results might overestimate the prevalence of myopia among primary school students. However, in the COMET longitudinal study, little difference was found between both cycloplegic and noncycloplegic refractive errors, ${ }^{52}$ and this may also not affect the difference in myopia prevalence rate between the north and the south in China. Secondly, the risk factors evaluated were limited. We did not evaluate the exact time spent for outdoor activities. The annual average sunshine duration in different cities only represented the potential daylight exposure. Wearable monitors such as light meters should be further used to evaluate the actual amount and duration of exposure to sunlight.

In conclusion, this study demonstrated that southern Chinese cities showed higher myopia prevalence than northern ones, and myopia was associated with shorter sunshine duration, higher education level and female gender. These findings confirmed that daylight exposure contributed to a protective role against myopia development. As a result, children should be encouraged to engage in various outdoor activities during the day.

\section{Author Contributions}

All authors contributed to data analysis, drafting or revising the article, have agreed on the journal to which the article was submitted, gave final approval of the version to be published, and agree to be accountable for all aspects of the work.

\section{Funding}

This work was supported by Consulting and research project of Chinese Academy of Engineering (2019-xy-84), Academic promotion plan of Shandong First Medical University \& Shandong Academy of Medical Sciences (2019ZL001), and Medical and Health Development Grant of Shandong Province, China (202007020431).

\section{Disclosure}

The authors declared no conflicts of interest for this work and no potential conflicts of interest with respect to the research, authorship, and/or publication of this article.

\section{References}

1. Holden BA, Fricke TR, Wilson DA, et al. Global prevalence of myopia and high myopia and temporal trends from 2000 through 2050. Ophthalmology. 2016;123:1036-1042. doi:10.1136/bjophthalmol-2017-311266

2. Li FF, Yam JC. Low-concentration atropine eye drops for myopia progression. Asia Pac J Ophthalmol. 2019;8:360-365. doi:10.1097/ APO.0000000000000256

3. Yang Y, Li R, Ting D, et al. The associations of high academic performance with childhood ametropia prevalence and myopia development in China. Ann Transl Med. 2021;9:745. doi:10.21037/atm-208069

4. Wang NL, Li SM, Wei SF. The key points and difficulties in prevention of myopia in Chinese children and adolescents. Zhonghua Yan Ke Za Zhi. 2021;57:241-244.

5. Bilbao MV, Recalde S, Bezunartea J, et al. Genetic and environmental factors related to the development of myopic maculopathy in Spanish patients. PLoS One. 2020;15:e236071. doi:10.1371/journal.pone. 0236071

6. Lee KM, Kim M, Oh S, et al. Hemisphere opposite to vascular trunk deviation is earlier affected by glaucomatous damage in myopic high-tension glaucoma. PLoS One. 2020;15:e233270. doi:10.1371/ journal.pone. 0233270

7. Min SK, Sang JP, Park KH, et al. Different mechanistic association of myopia with rhegmatogenous retinal detachment between young and elderly patients. Biomed Res Int. 2019;2019:5357241. doi:10.1155/ 2019/5357241

8. Foo LL, Ng WY, Lim G, et al. Artificial intelligence in myopia: current and future trends. Curr Opin Ophthalmol. 2021;32 (5):413-424. doi:10.1097/ICU.0000000000000791

9. Baird PN, Saw SM, Lanca C, et al. Myopia. Nat Rev Dis Primers. 2020;6:99. doi:10.1038/s41572-020-00231-4

10. Hysi PG, Choquet H, Khawaja AP, et al. Meta-analysis of 542,934 subjects of European ancestry identifies new genes and mechanisms predisposing to refractive error and myopia. Nat Genet. 2020;52:401-407. doi:10.1038/s41588-020-0599-0

11. Chou HD, Yao TC, Huang YS, et al. Myopia in school-aged children with preterm birth: the roles of time spent outdoors and serum vitamin D. $B r \quad J$ Ophthalmo. 2021;105:468-472. doi:10.1136/ bjophthalmol-2019-315663

12. Guggenheim JA, Northstone K, McMahon G, et al. Time outdoors and physical activity as predictors of incident myopia in childhood: a prospective cohort study. Invest Ophthalmol Vis Sci. 2012;53:2856-2865. doi:10.1167/iovs.11-90911

13. Cui D, Trier K, Munk Ribel-Madsen S. Effect of day length on eye growth, myopia progression, and change of corneal power in myopic children. Ophthalmology. 2013;120:1074-1079. doi:10.1016/j. ophtha.2012.10.022

14. Donovan L, Sankaridurg P, Ho A, et al. Myopia progression in Chinese children is slower in summer than in winter. Optom Vis Sci. 2012;89:1196-1202. doi:10.1097/OPX.0b013e3182640996

15. Gwiazda J, Deng L, Manny R, et al.; COMET Study Group. Seasonal variations in the progression of myopia in children enrolled in the correction of myopia evaluation trial. Invest Ophthalmol Vis Sci. 2014;55:752-758. doi:10.1167/iovs.13-13029

16. Cai XB, Shen SR, Chen DF, et al. An overview of myopia genetics. Exp Eye Res. 2019;188:107778. doi:10.1016/j.exer.2019.107778

17. Pan $\mathrm{CW}, \mathrm{Wu} \mathrm{RK}, \mathrm{Li} \mathrm{J}$, et al. Low prevalence of myopia among school children in rural China. BMC Ophthalmol. 2018;18:140. doi:10.1186/s12886-018-0808-0

18. Sun JT, An M, Yan XB, et al. Prevalence and related factors for myopia in school-aged children in Qingdao. $J$ Ophthalmol. 2018;2018:9781987. doi:10.1155/2018/9781987

19. Naing L, Winn T, Rusli BN. Practical issues in calculating the sample size for prevalence studies. Arch Orofac Sci. 2006;1:9-14. 
20. Sun J, Zhou J, Zhao P, et al. High prevalence of myopia and high myopia in 5060 Chinese university students in Shanghai. Invest Ophthalmol Vis Sci. 2012;53:7504-7509. doi:10.1167/iovs.11-8343

21. Negrel AD, Maul E, Pokharel GP, et al. Refractive error study in children: sampling and measurement methods for a multicountry survey. Am J Ophthalmol. 2000;129:421-426. doi:10.1016/S00029394(99)00455-9

22. Casson RJ, Kahawita S, Kong A, et al. Exceptionally low prevalence of refractive error and visual impairment in schoolchildren from Lao People's Democratic Republic. Ophthalmology. 2012;119:2021-2027. doi:10.1016/j.ophtha.2012.03.049

23. Thorn F, Chen J, Li C, et al. Refractive status and prevalence of myopia among Chinese primary school students. Clin Exp Optom. 2020;103:177-183. doi:10.1111/cxo.12980

24. Wang J, Ying GS, Fu X, et al. Prevalence of myopia and vision impairment in school students in Eastern China. BMC Ophthalmol. 2020;20:2. doi:10.1186/s12886-019-1281-0

25. Lim DH, Han J, Chung TY, et al. The high prevalence of myopia in Korean children with influence of parental refractive errors: the 2008-2012 Korean National Health and Nutrition Examination Survey. PLoS One. 2018;13:e0207690. doi:10.1371/journal. pone.0209876

26. Pokharel GP, Negrel AD, Munoz SR, et al. Refractive error study in children: results from Mechi Zone, Nepal. Am J Ophthalmol. 2000;129:436-444. doi:10.1016/s0002-9394(99)00453-5

27. Morgan IG, Wu PC, Ostrin LA, et al. IMI risk factors for myopia. Invest Ophthalmol Vis Sci. 2021;62:3. doi:10.1167/iovs.62.5.3

28. Jonas JB, Ang M, Cho P, et al. IMI prevention of myopia and its progression. Invest Ophthalmol Vis Sci. 2021;62(5):6. doi:10.1167/ iovs. 62.5 .6

29. Wang SK, Guo Y, Liao C, et al. Incidence of and factors associated with myopia and high myopia in Chinese children, based on refraction without cycloplegia. JAMA Ophthalmol. 2018;136 (9):1017-1024. doi:10.1001/jamaophthalmol.2018.2658

30. Wang J, Li Y, Musch DC, et al. Progression of myopia in school-aged children after COVID-19 home confinement. JAMA Ophthalmol. 2021;139(3):293-300. doi:10.1001/jamaophthalmol.2020.6239

31. Saw SM, Katz J, Schein OD, et al. Epidemiology of myopia. Epidemiol Rev. 1996;18:175-187. doi:10.1093/oxfordjournals.epirev. a017924

32. Tang Y, Chen A, Zou M, et al. Prevalence and time trends of refractive error in Chinese children: a systematic review and meta-analysis. J Glob Health. 2021;11:08006. doi:10.7189/ jogh.11.08006

33. Hagen LA, Gjelle JVB, Arnegard S, et al. Prevalence and possible factors of myopia in Norwegian adolescents. Sci Rep. 2018;8 (1):13479. doi:10.1038/s41598-018-31790-y

34. McCullough SJ, O’Donoghue L, Saunders KJ. Six year refractive change among white children and young adults: evidence for significant increase in myopia among white UK children. PLoS One. 2016;11(1):e0146332. doi:10.1371/journal.pone.0146332

35. Azuara-Blanco A, Logan N, Strang N, et al. Low-dose $(0.01 \%)$ atropine eye-drops to reduce progression of myopia in children: a multicentre placebo-controlled randomised trial in the UK (CHAMP-UK)-study protocol. $B r \quad J$ Ophthalmol. 2020;104 (7):950-955. doi:10.1136/bjophthalmol-2019-314819

36. Xiong S, Sankaridurg P, Naduvilath T, et al. Time spent in outdoor activities in relation to myopia prevention and control: a meta-analysis and systematic review. Acta Ophthalmol. 2017;95 (6):551-566. doi:10.1111/aos.13403
37. Rose KA, Morgan IG, Ip J, et al. Outdoor activity reduces the prevalence of myopia in children. Ophthalmology. 2008;115:1279-1285. doi:10.1016/j.ophtha.2007.12.019

38. Kearney S, O’Donoghue L, Pourshahidi LK, et al. Conjunctival ultraviolet autofluorescence area, but not intensity, is associated with myopia. Clin Exp Optom. 2019;102(1):43-50. doi:10.1111/ cxo. 12825

39. Kumar S, Gupta N, Velpandian T, et al. Myopia, melatonin and conjunctival ultraviolet autofluorescence: a comparative cross-sectional study in Indian myopes. Curr Eye Res. 2021:1-8. doi:10.1080/02713683.2021.1894580

40. Kearney S, O’Donoghue L, Pourshahidi LK, et al. The use of conjunctival ultraviolet autofluorescence (CUVAF) as a biomarker of time spent outdoors. Ophthalmic Physiol Opt. 2016;36(4):359-369. doi:10.1111/opo.12309

41. Zhou X, Pardue MT, Iuvone PM, et al. Dopamine signaling and myopia development: what are the key challenges. Prog Retin Eye Res. 2017;61:60-71. doi:10.1016/j.preteyeres.2017.06.003

42. Spillmann L. Stopping the rise of myopia in Asia. Graefes Arch Clin Exp Ophthalmol. 2020;258(5):943-959. doi:10.1007/s00417-01904555-0

43. Landis EG, Chrenek MA, Chakraborty R, et al. Increased endogenous dopamine prevents myopia in mice. Exp Eye Res. 2020;193:107956. doi:10.1016/j.exer.2020.107956

44. Zhang S, Yang J, Reinach PS, et al. Dopamine receptor subtypes mediate opposing effects on form deprivation myopia in pigmented guinea pigs. Invest Ophthalmol Vis Sci. 2018;59(11):4441-4448. doi:10.1167/iovs.17-21574

45. Mirshahi A, Ponto KA, Hoehn R, et al. Myopia and level of education: results from the Gutenberg Health Study. Ophthalmology. 2014;121(10):2047-2052. doi:10.1016/j.ophtha.2014.04.017

46. Verhoeven VJ, Buitendijk GH, Rivadeneira F, et al.. Education influences the role of genetics in myopia. Eur $J$ Epidemiol. 2013;28 (12):973-980. doi:10.1007/s10654-013-9856-1

47. Huang L, Kawasaki H, Liu Y, Wang Z. The prevalence of myopia and the factors associated with it among university students in Nanjing: a cross-sectional study. Medicine. 2019;98(10):e14777. doi:10.1097/MD.0000000000014777

48. Morgan IG, Rose KA. Myopia and international educational performance. Ophthalmic Physiol Opt. 2013;33:329-338. doi:10.1111/opo.12040

49. Yotsukura E, Torii H, Inokuchi $\mathrm{M}$, et al. Current prevalence of myopia and association of myopia with environmental factors among schoolchildren in Japan. JAMA Ophthalmol. 2019;137:1233-1239. doi:10.1001/jamaophthalmol.2019.3103

50. Hinterlong JE, Holton VL, Chiang CC, et al. Association of multimedia teaching with myopia: a national study of school children. J Adv Nurs. 2019;75:3643-3653. doi:10.1111/jan.14206

51. Vainer I, Mimouni M, Rabina G, et al. Age- and gender-related characteristics of corneal refractive parameters in a large cohort study. Am J Ophthalmol. 2020;209:45-54. doi:10.1016/j. ajo.2019.09.007

52. Gwiazda J, Marsh-Tootle WL, Hyman L, et al. Baseline refractive and ocular component measures of children enrolled in the correction of myopia evaluation trial (COMET). Invest Ophthalmol Vis Sci. 2002;43:314-321. doi:10.1021/ol100822k 


\section{Publish your work in this journal}

The International Journal of General Medicine is an international, peer-reviewed open-access journal that focuses on general and internal medicine, pathogenesis, epidemiology, diagnosis, monitoring and treatment protocols. The journal is characterized by the rapid reporting of reviews, original research and clinical studies across all disease areas. The manuscript management system is completely online and includes a very quick and fair peer-review system, which is all easy to use. Visit http://www.dovepress.com/ testimonials.php to read real quotes from published authors.

Submit your manuscript here: https://www.dovepress.com/international-journal-of-general-medicine-journal 